\title{
A mouse model of the 15q13.3 microdeletion syndrome shows prefrontal neurophysiological dysfunctions and attentional impairment
}

\author{
Simon R. O. Nilsson ${ }^{1,2,3} \cdot$ Pau Celada $^{4,5} \cdot$ Kim Fejgin $^{6} \cdot$ Jonas Thelin $^{6,7} \cdot$ Jacob Nielsen $^{6}$ • \\ Noemí Santana $^{4,5}$. Christopher J. Heath ${ }^{1,2,8}$ • Peter H. Larsen ${ }^{6}$ - Vibeke Nielsen ${ }^{6}$. \\ Brianne A. Kent ${ }^{1,2}$ - Lisa M. Saksida ${ }^{1,2}$. Tine B. Stensbøl ${ }^{6}$. Trevor W. Robbins ${ }^{1,2}$. \\ Jesper F. Bastlund ${ }^{6}$. Timothy J. Bussey ${ }^{1,2}$ • Francesc Artigas ${ }^{4,5} \cdot$ Michael Didriksen $^{6}$
}

Received: 6 January 2016 / Accepted: 25 February 2016/Published online: 17 March 2016

(C) The Author(s) 2016. This article is published with open access at Springerlink.com

\begin{abstract}
Rationale A microdeletion at locus $15 \mathrm{q} 13.3$ is associated with high incidence rates of psychopathology, including schizophrenia. A mouse model of the 15q13.3 microdeletion syndrome has been generated (Df[h15q13]/+) with translational utility for modelling schizophrenia-like pathology. Among other deficits, schizophrenia is characterised by dysfunctions in prefrontal cortical (PFC) inhibitory circuitry and attention. Objectives The objective of this study is to assess PFCdependent functioning in the $\mathrm{Df}(\mathrm{h} 15 \mathrm{q} 13) /+$ mouse using electrophysiological, pharmacological, and behavioural assays.

Method Experiments 1-2 investigated baseline firing and auditory-evoked responses of PFC interneurons and pyramidal neurons. Experiment 3 measured pyramidal firing in response to intra-PFC $\mathrm{GABA}_{\mathrm{A}}$ receptor antagonism. Experiments 4-6 assessed PFC-dependent attentional functioning through the touchscreen 5-choice serial reaction time
\end{abstract}

Timothy J. Bussey, Francesc Artigas and Michael Didriksen contributed equally to this work.

Electronic supplementary material The online version of this article (doi:10.1007/s00213-016-4265-2) contains supplementary material, which is available to authorized users.

Simon R. O. Nilsson

sn440@cam.ac.uk

1 Department of Psychology, University of Cambridge, Cambridge CB2 3EB, UK

2 MRC and Wellcome Trust Behavioural and Clinical Neuroscience Institute, University of Cambridge, Cambridge CB2 3EB, UK

3 Department of Psychology, State University of New York at Binghamton, Binghamton, NY 13902-6000, USA task (5-CSRTT). Experiments 7-12 assessed reversal learning, paired-associate learning, extinction learning, progressive ratio, trial-unique non-match to sample, and object recognition.

Results In experiments $1-3$, the $\operatorname{Df}(\mathrm{h} 15 \mathrm{q} 13) /+$ mouse showed reduced baseline firing rate of fast-spiking interneurons and in the ability of the $\mathrm{GABA}_{\mathrm{A}}$ receptor antagonist gabazine to increase the firing rate of pyramidal neurons. In assays of auditory-evoked responses, PFC interneurons in the Df (h15q13)/+ mouse had reduced detection amplitudes and increased detection latencies, while pyramidal neurons showed increased detection latencies. In experiments $4-6$, the $\operatorname{Df}(\mathrm{h} 15 \mathrm{q} 13) /+$ mouse showed a stimulus duration-dependent decrease in percent accuracy in the 5-CSRTT. The impairment was insensitive to treatment with the partial $\alpha_{7} \mathrm{nAChR}$ agonist EVP-6124. The Df(h15q13)/+ mouse showed no cognitive impairments in experiments 7-12.
4 Institut d'Investigacions Biomèdiques de Barcelona, CSIC-IDIBAPS, Barcelona, Spain

5 Centro de Investigación Biomédica en Red de Salud Mental (CIBERSAM), Barcelona, Spain

6 H. Lundbeck A/S, Synaptic Transmission, Neuroscience Research DK, Ottiliavej 9, Valby 2500, Denmark

7 Neuronano Research Center, Lund University, 22381 Lund, Sweden

8 Department of Life, Health and Chemical Sciences, The Open University, Walton Hall, Milton Keynes MK7 6AA, UK 
Conclusion The Df(h15q13)/+ mouse has multiple dysfunctions converging on disrupted PFC processing as measured by several independent assays of inhibitory transmission and attentional function.

Keywords Copy number variation $\cdot 15 \mathrm{q} 13.3 \cdot$ Animal model $\cdot$ Chrna $7 \cdot$ Prefrontal cortex $\cdot$ Neurophysiology . Cognition

\section{Introduction}

The $15 \mathrm{q} 13.3$ microdeletion syndrome (15q13.3DS) is caused by a rare ( 1:30000 births) (LePichon et al. 2010) copy number variant $(\mathrm{CNV})$ with hemizygosity of at least seven genes on the long arm of chromosome 15 . The microdeletion is associated with variable cognitive impairment and psychiatric or neurological disorders (Miller et al. 2009), including autism (Pagnamenta et al. 2009; Ben-Shachar et al. 2009), attention deficit hyperactivity disorder (Miller et al. 2009), obsessive compulsive disorder (Melchior et al. 2013), and epilepsy (Helbig et al. 2009). $15 q 13.3 \mathrm{DS}$ is also associated with a $\sim 10$-fold increase in the risk of schizophrenia (International Schizophrenia Consortium 2008; Stefansson et al. 2014), making it one of the strongest known genetic risk factors for the disorder.

Among other alterations, the pathophysiology of schizophrenia is underpinned by imbalances within local prefrontal cortical (PFC) circuitry, typically observed as reductions in markers for cortical inhibitory signalling efficacy in histological (Lewis et al. 2005) and neurophysiological assays (Daskalakis et al. 2007; Javitt et al. 2008). Moreover, schizophrenia is characterised by core prefrontal-dependent "executive" cognitive impairments (Robbins 1990), perhaps most notably within the domain of attention (Carter and Barch 2007). Deficits in executive functioning have also been linked to dysregulated cortical recruitment and asynchronous activity partly produced by disrupted inhibitory activity during cognitive demand (Bickel and Javitt 2009; Nakazawa et al. 2012). Indeed, schizophrenia-related dysfunctions observed in measures of event-related neuronal responses are associated with attentional impairment (Nieman et al. 2002). The critical $15 \mathrm{q} 13.3$ segment also encompasses the CHRNA7 gene, which is involved in cortical inhibitory transmission (Adams et al. 2012; Lin et al. 2014), regulates schizophrenia-relevant neurophysiological markers (Hajos et al. 2005), and is associated with attentional dysfunction (Adler et al. 1998; Young et al. 2004). The cognitive phenotypes associated with 15q13.3DS remain imprecisely defined and unspecific deficits typically ranging from moderate to mild intellectual disability have been described (Lowther et al. 2014; Gillentine and Schaaf 2015). The 15q13.3DS has also been associated with attentional impairments that can be independent of general intellectual functioning (Miller et al. 2009).
Preclinical lesion and local microinfusion studies have shown attentional functioning to be contingent on the activity in the medial prefrontal cortex (mPFC), including the prelimbic cortex (PrL) (Muir et al. 1996; Chudasama and Muir 2001; Passetti et al. 2002) and GABAergic activity in this area (Paine et al. 2011; Pehrson et al. 2013; Pezze et al. 2014). Recordings in animals during cognitive testing further indicate that inhibitory PrL-activity correlates with attentional performance in the 5-choice serial reaction time task (5CSRTT) (Totah et al. 2009). We have previously generated a mouse model of the 15q13.3DS (Df[h15q13]/+) which shows $50 \%$ reduction in messenger RNA (mRNA) expression of the genes in the region and several 15q13.3DS- and schizophrenia-like phenotypes, including decreases in the amplitude of cortical auditory-evoked potentials and aberrant responding to $\mathrm{GABA}_{\mathrm{A}}$ receptor $\left(\mathrm{GABA}_{\mathrm{A}} \mathrm{R}\right)$ antagonism in seizure assays (Fejgin et al. 2014).

As part of the NEWMEDS initiative (Innovative Medicines Initiative Grant Agreement No. 115008), the current study tested the translational utility of the $\mathrm{Df}(\mathrm{h} 15 \mathrm{q} 13) /+$ mouse for schizophrenia-relevant cortical-dependent dysfunctions using multiple parallel experimental approaches. These approaches included measures of (i) pre-attentative processing through auditory-evoked neural responses, (ii) higher order executive attention through the touchscreen 5-CSRTT, and (iii) mechanistic processes through concurrent intra-PFC GABAergic pharmacology and measures of pyramidal neuron spontaneous discharge rates.

\section{Methods and materials}

\section{Animals}

The Df(h15q13)/+ mouse was generated by Taconic Artemis (Köln, Germany) as previously described (Fejgin et al. 2014). The Df(h15q13)/+ mice were of a c57BL/6NTac background. All experiments used male mice. Animals were housed under a 12-h light/dark cycle with stable temperature and humidity conditions with ad libitum access to food and water. Experiments 1-2 investigated baseline and auditory-evoked neural responses of putative pyramidal cells and interneurons and used 14 mice (age 10-14 weeks; wild type (WT) $N=7$, $\operatorname{Df}(\mathrm{h} 15 \mathrm{q} 13) /+N=7)$. Experiment 3 analysed pyramidal neuron responses to $\mathrm{GABA}_{\mathrm{A}} \mathrm{R}$ antagonism and used 19 mice (age 10-14 weeks; WT $N=10, \operatorname{Df}(\mathrm{h} 15 \mathrm{q} 13) /+N=9)$. Experiments 4-12 assessed cognitive functions and used three cohorts of animals (each cohort: WT $N=16, \operatorname{Df}(\mathrm{h} 15 \mathrm{q} 13) /+N=16$; age at start of testing: 10 weeks). Prior to cognitive testing, animals were food restricted and maintained at about $85 \%$ of their free-feeding weight. Cohort 1 was tested on the 5-CSRTT (experiments 4-6) and novel object recognition (experiment 12). Cohort 2 was tested on visual discrimination and reversal 
learning (experiment 7), paired-associate learning (PAL) (experiment 8), trial-unique non-match to sample (TUNL) (experiments 11), and extinction learning (experiment 10 ). Cohort 3 was tested on progressive ratio (experiment 9). The experiments followed the European Union regulation (directive 2010/63 of 22 September 2010) and UK Animals (Scientific Procedures) Act 1986 and were approved by the Barcelona School of Medicine Institutional Animal Care and Use Committee and the Danish National Committee for Ethics in Animal Experimentation.

\section{Experiments 1-2: cortical auditory-evoked neuronal firing}

Surgical procedures Mice were anesthetised with Sevoflurane (Abbott Scandinavia AB, Solna, Sweden), and body temperature was maintained at $37{ }^{\circ} \mathrm{C}$ by an isothermal heating pad. A 16-channel array electrode (Innovative Neurophysiology, Durham, NC) was placed in the PrL at stereotaxic coordinates (from bregma and duramater) AP: $+1.9 \mathrm{~mm}$, L: $+0.2 \mathrm{~mm}$, and DV: $-1.5 \mathrm{~mm}$ according to the mouse brain atlas (Paxinos and Franklin 2008) and secured through a set of skull-mounted anchor screws (over the cerebellum and contralateral to the prefrontal cortex electrode) and dental cement (3M relyX unicem self-adhesive universal resin cement). A small hole for ground wires was drilled adjacent to the cerebellum anchor screw. Mice were treated with a prophylactic antibiotic $\left(5 \mathrm{mg} / \mathrm{kg}\right.$, s.c., Baytril vet ${ }^{\circledR}, 50 \mathrm{mg} / \mathrm{ml}$ Enrofloxacin, Bayer, Germany) and peripheral analgesic $\left(1.5 \mathrm{mg} / \mathrm{kg}\right.$, s.c., Rimadyl vet ${ }^{\mathbb{}}, 50 \mathrm{mg} / \mathrm{ml}$ Carprofen, Pfizer, USA) pre-surgery and for 5 days post-surgery. Mice were allowed $\geq 1$ week of post-surgical recovery.

Signal acquisition Activity of a large number of PrL neurons was recorded in freely behaving animals. Single- and multiunit activities were recorded using a multichannel recording system (Plexon Inc. Dallas, TX). Continuously recorded data was band pass-filtered in order to avoid low frequency activity and visualise the action potentials. Frequencies below $300 \mathrm{~Hz}$ were filtered to delete the slow components of the raw data, and the upper cut-off frequency of $9000 \mathrm{~Hz}$ was applied to diminish the noisy appearance of the action potential shape (Quian Quiroga 2009). After filtering, action potentials were easily visualised on top of background noise activity and could be detected by using an amplitude threshold. Storage threshold for spiking events was three standard deviations of the peak height histogram of filtered signal. Artifact waveforms were removed, and the spike waveform minima were aligned using the Offline Sorter software (v3.2; Plexon, Dallas, TX).

Spike sorting and classification Action potentials were sorted into unit clusters using the Offline Sorter software.
Waveform features used for separating the units were the first three principal components of the sampled waveforms for a given dataset. A cluster was classified as a single unit when $<0.3 \%$ of the spikes occurred within a 2 -ms refractory period. To group units in putative cell types, we extracted two features from the average waveform: valley full width at half maximum and peak-to-valley time. The waveform features were plotted and used to classify the units as putative pyramidal cells or putative fast-spiking interneurons (Barthó et al. 2004) (see Supplementary Fig. 1a). Waveforms with a valley full width at half maximum duration $<0.35 \mathrm{~ms}$ and valley to peak time $<0.2 \mathrm{~ms}$ were considered interneurons, while waveforms with a half amplitude duration $>0.37 \mathrm{~ms}$ and valley to peak time $>0.15 \mathrm{~ms}$ were considered pyramidal cells. Waveforms not falling into one of the two groups were considered as intermediates and were not included for further analysis.

Auditory gating paradigm Mice were tested in the dark phase and were habituated to the recording chamber for $40 \mathrm{~min}$ prior to the beginning of the session. Motor activity was manually monitored via an infrared camera, and recordings were made during resting state where periods with locomotor activity were excluded from analysis. Paired white noise auditory stimuli (white noise, $82 \mathrm{~dB}, 10 \mathrm{~ms}$ duration with $1 \mathrm{~ms}$ rise and fall, inter-stimulus interval $500 \mathrm{~ms}$ ) were presented with an inter-pair interval of $10 \mathrm{~s}$, and simultaneous recordings of single-unit activity were made for $10 \mathrm{~min}$. A transistor-transistor logic (TTL) pulse $50 \mathrm{~ms}$ prior to the sound was used as event mark and saved together with single-unit data. Startle responses were not observed during the recording sessions. Peri-stimulus time histograms (PSTH) were constructed for each spike train with a bin width of $1 \mathrm{~ms}$. The average PSTH across units were calculated after baseline subtraction (baseline interval: -1.4 to $-0.4 \mathrm{~s}$ relative to first pulse) of each unit PSTH. The response amplitude was measured in a $30-\mathrm{ms}$ bin starting $10 \mathrm{~ms}$ after the stimulus onset. The latency was set to the first $1 \mathrm{~ms}$ bin that was significantly higher than the baseline firing rate.

\section{Experiment 3: intra-mPFC GABA $A_{A} R$ antagonism and pyramidal discharge rate}

Surgical procedures Mice were anesthetised by acute dose of chloral hydrate $(400 \mathrm{mg} / \mathrm{kg}$ i.p) and maintenance dose of $\sim 1 \mathrm{mg} / \mathrm{kg} / \mathrm{min}$ i.p using a perfusion pump. A heating pad maintained body temperature at $37^{\circ} \mathrm{C}$. Single-unit recordings were performed using glass micropipettes pulled from 2-mm capillary glass (World Precision Instruments, Sarasota, FL) and a Narishige PE-2 pipette puller (Tokyo, Japan). Recorded signals were amplified $(\times 10$; Neurodata IR283 amplifier, Cygnus Technology Inc., Delaware Water Gap, PA), post-amplified and filtered $(\times 100$; band pass filter: $30 \mathrm{~Hz}-$ 

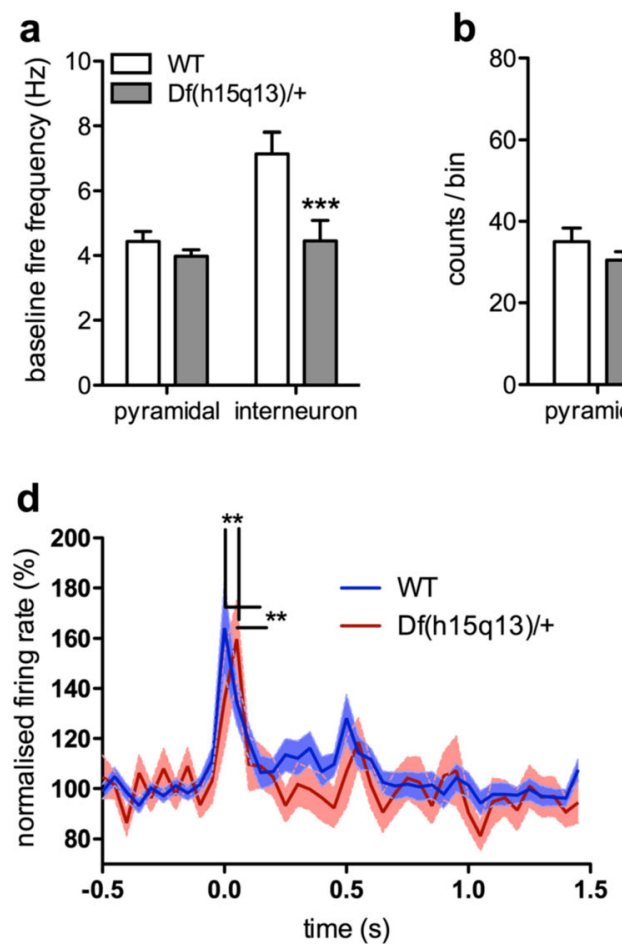

Fig. 1 Prefrontal cortical electrophysiological characterisations of $\mathrm{Df}(\mathrm{h} 15 \mathrm{q} 13) /+$ and WT littermates. Data are presented as means \pm SEM. a Baseline firing frequencies. The $\operatorname{Df}(\mathrm{h} 15 \mathrm{q} 13) /+$ mouse had attenuated baseline firing frequencies of PrL putative fast-spiking interneurons but not principal cells. b Response amplitudes. The Df(h15q13)/+ mouse had decreased detection amplitude in PrL putative fast-spiking interneurons but not principal cells. c Neuron onset latencies. The Df(h15q13)/+ had delayed onset latencies of both pyramidal cells and putative fast-spiking

$10 \mathrm{kHz}$ ) (Cibertec amplifier/filter, Madrid, Spain) and analysed using a DAT 1401plus interface system (Spike2, Cambridge Electronic Design, Cambridge, UK).

Intra-mPFC gabazine Spontaneous discharge rates of putative pyramidal neurons in $\mathrm{Df}(\mathrm{h} 15 \mathrm{q} 13) /+$ and WT mice were analysed during control conditions and following local $\mathrm{GABA}_{\mathrm{A}} \mathrm{R}$ antagonism as described in rat PFC (Lladó-Pelfort et al. 2012). Electrodes (impedances: 6-12 M 2 ) containing saline $2 \mathrm{M}$ or gabazine $(20 \mathrm{mM}$, dissolved in $0.2 \mathrm{M} \mathrm{NaCl}$; SR95531, Sigma-Aldrich, St Louis, MO) were placed at stereotaxic coordinates (from bregma) AP: $+2.1 \mathrm{~mm}, \mathrm{~L}:-0.2-$ $0.4 \mathrm{~mm}$. Pyramidal neuron discharge was examined in the same mice in standard $(\mathrm{NaCl})$ or gabazine conditions by performing track descents in both conditions. Electrode descents were made at DV: $-1-2.5 \mathrm{~mm}$ (from duramater) according to the mouse brain atlas (Paxinos and Franklin 2008). Pyramidal neurons were identified by their electrophysiological characteristics: (i) duration of the depolarisation phase of the action potential (average of 10 spikes) and (ii) discharge rate (Lladó-Pelfort et al. 2012) (see Supplementary Fig. 1b). Gabazine was chosen due to its superior selectivity
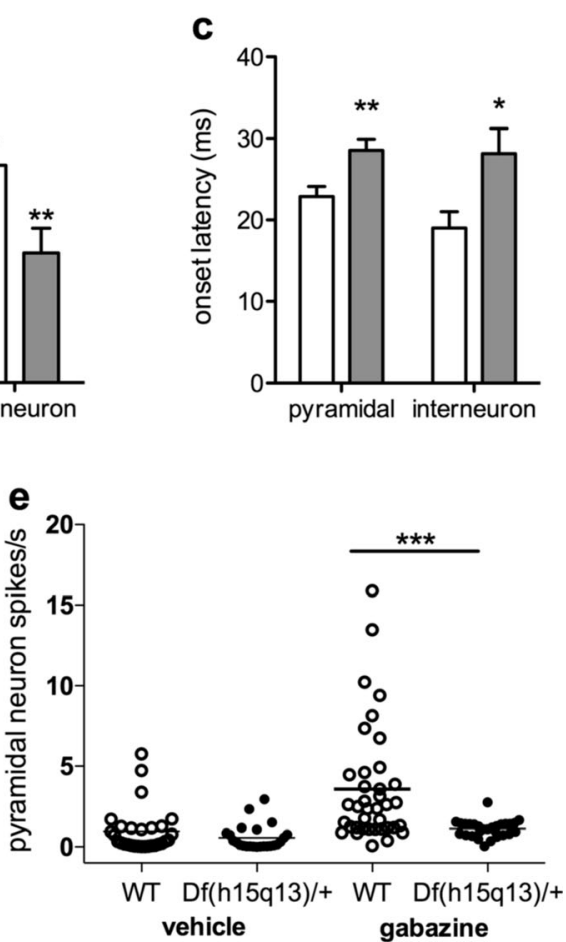

interneurons following auditory stimulation. d Average cortical putative fast-spiking interneuron response. Reduced firing rates and delayed onset of $\mathrm{Df}(\mathrm{h} 15 \mathrm{q} 13) /+$ prelimbic interneurons relative to WT mice in the auditory double-click paradigm. e Gabazine-induced elevation of PFC pyramidal spike frequency. The $\operatorname{Df}(\mathrm{h} 15 \mathrm{q} 13) /+$ showed decreased sensitivity to intra-mPFC $\mathrm{GABA}_{\mathrm{A}} \mathrm{R}$ antagonism on pyramidal neuron spike frequency. Asterisks denote $p<0.05(* p<0.05, * * p<0.01$, $* * * p<0.001)$

relative to the classical $\mathrm{GABA}_{\mathrm{A}} \mathrm{R}$ antagonist bicuculline (Debarbieux et al. 1998; Stocker et al. 1999). Electrode tips (5-7- $\mu \mathrm{m}$ diameter) were broken to a final resistance of 9$15 \mathrm{M} \Omega$. Gabazine reached recorded neurons through passive diffusion from the electrode as previously shown for bicuculline (Steward et al. 1990; Tepper et al. 1995). To obtain a reliable measure of spontaneous discharge rate, a 5-min recording was made for each putative pyramidal neuron after which the electrode was descended again.

\section{Experiments 4-6: the 5-choice serial reaction time task}

Apparatus The 5-CSRTT experiments used 32 operant touchscreen chambers (Campden Instruments, Loughborough, UK) extensively described elsewhere (Horner et al. 2013; Mar et al. 2013).

5-choice serial reaction time task (5-CSRTT) The 5-CSRTT is a rodent analogue of the human continuous performance task (CPT) measuring attention in which schizophrenic patients show impairments (Kahn et al. 2012). The 5-CSRTT is sensitive to $\mathrm{mPFC}$ lesions (Muir et al. 1996; Chudasama 
and Muir 2001; Passetti et al. 2002) and perturbations to mPFC inhibitory signalling in the rodent (Paine et al. 2011; Pehrson et al. 2013; Pezze et al. 2014) and impulsive and attentional impairments in mouse models of neuropsychiatric disorders (Young et al. 2004; Hoyle et al. 2006; Romberg et al. 2011). The task is described in extensive detail elsewhere (Mar et al. 2013). Briefly, animals were initially trained to respond to a white-square stimulus using a 2-s stimulus duration (SD), 40-trial session length, and 5-s delay. Once the animals had acquired the criterion of $\geq 80 \%$ accuracy and $\leq 20 \%$ for two consecutive sessions, they were tested on a series of probe tests. Each probe test lasted for two consecutive sessions, and the presented data represents the means for these 2 days (Romberg et al. 2011). These probe tests were always presented in order of increasing difficulty (i.e., SD probes were presented in order of decreasing durations, and delay probes were presented in order of increasing delays). During probe tests the animals were tested for 7 days a week. Between each probe test, the animals had to reacquire the criteria of $\geq 80 \%$ accuracy and $\leq 20 \%$ omissions for two consecutive sessions on the baseline task parameters of 2-s SD and 5-s delay. These baseline sessions were done in order to reduce potential proactive interference from previous probe tests (Romberg et al. 2011; Mar et al. 2013).

In experiment 4 , the animals were initially tested on probe tests of increasing attentional demand by decreasing SDs (1.6, $1.0,0.8,0.6,0.4,0.2 \mathrm{~s})$. Animals were then given tests of motor impulsivity by increasing delays (7, 9, 11, $13 \mathrm{~s})$. Next, the animals were given tests of vigilance through increased session lengths ( 80 trials, followed by 140 trials). At each of these session lengths, the animals were tested on decreasing SDs $(1.6,1,0.8,0.6 \mathrm{~s})$. In experiment 5 , the test of 140 trials per session was repeated using $1.6,1,0.8,0.6,0.4$, and $0.2 \mathrm{~s}$ SDs. Moreover, much recent focus has been on the therapeutic potentials of the partial $\alpha_{7}$ nicotinic acetylcholine receptor $\left(\alpha_{7} \mathrm{nAChR}\right)$ agonist EVP-6124 against the cognitive deficits of schizophrenia (Garay et al. 2016). In experiment 6, animals were treated with EVP-6124 (Latin-square design; 0, 3, 10, $30 \mathrm{mg} / \mathrm{kg}, 10 \mathrm{ml} / \mathrm{kg}, 30 \mathrm{~min}$ pre-treatment time, i.p; EnVivo Pharmaceuticals) and tested again on the 140 trials, 0.8-s SD, and 5-s delay parameter. Each dose-phase was separated by $48 \mathrm{~h}$. Animals were tested drug-free on the baseline parameters (140 trials, 2-s SD, 5-s delay) on sessions separating each dose-phase. Prior to commencing the Latin-square, animals were given two saline injections for habituation to the injection procedure.

The dependent variables were completed trials, percent accuracy (total number of correct trials divided by total number of correct and incorrect trials), percent omission (total number of omitted trials divided by the total number of trials), percent premature responses (total number of premature trials divided by the total number of trials), percent perseverative correct (total number of perseverative responses to the correct location divided by the total number of correct responses), and average response latency and average reward retrieval latency. Each session was also divided into 10-trial bins, and the dependent measures were calculated within each 10-trial bin.

\section{Experiments 7-12: additional cognitive assays}

Apparatus The operant experiments used the same 32 touchscreen chambers that were used in experiments 4-6 (Campden Instruments, Loughborough, UK). The spontaneous object recognition experiment used two Y-shaped mazes made of Perspex.

Additional cognitive assays Experiment 7 assessed discrimination learning and reversal learning in two separate twochoice challenges; the first using more discriminable stimuli and the second using more challenging stimuli (see Fig. 3a, b, inset). The task is described elsewhere (Mar et al. 2013). The dependent variables for reversal learning were trials to criterion, incorrect responses to criterion, correction trials to criterion, perseverative errors (the number of incorrect responses made before achieving $>50 \%$ correct responding in session), learning errors (the number of incorrect responses made after achieving $\leq 50 \%$ correct responses correct responding in a session), average response latency, and average reward retrieval latency.

Experiment 8 assessed paired-associate learning (PAL). The task is extensively described elsewhere (Horner et al. 2013). Animals were tested for 70 sessions, and the data was collapsed into 5-session bins for analyses. The main dependent variables were percent accuracy (expressed as the number of correct responses divided by the total number of correct and incorrect responses), correction trials, average response latency, and average reward retrieval latency.

Experiment 9 assessed touchscreen progressive ratio (PR) by employing linear ramp schedules of $4,8,12$, and 16 touches. The task is extensively described elsewhere (Heath et al. 2015). The dependent variables were the total number of trials completed, breakpoint (defined as the number of screen responses emitted in the last successfully completed trial of the session), the total number of screen touches emitted during the session, and the number of "blank" location touches recorded during the session (corrected for total session time).

Experiment 10 assessed touchscreen extinction learning. The task is extensively described elsewhere (Mar et al. 2013). Within each session, the dependent variables were percent responses (the total number of responses divided by the number responses and omissions), the number of touchscreen responses during the ITI, and stimulus response latencies.

Experiment 11 used the touchscreen trial-unique non-match to sample (TUNL) task to assess working memory through increasing delays $(2,4,6$, and 8 s) 
followed by tests of decreasing stimuli separations to assess pattern separation (small, medium, large). The task is extensively described elsewhere (Oomen et al. 2013; Kim et al. 2015). The dependent variables were percent accuracy (total number of correct trials dived by the total number of correct and incorrect trials), percent correction trials (total number of correction trials dived by the total number of correct and incorrect trials), average response latency, and average reward retrieval latency.

Experiment 12 assessed novel object recognition using $8 \mathrm{~h}$ (trial 1) and $11 \mathrm{~h}$ (trial 2 and trial 3) delays. The tasks are extensively described elsewhere (Winters et al. 2008). Video analyses of behaviour were made by an experimenter blind to the genotype and location of the novel object using JWatcher (version 1.0). For each animal, the discrimination ratio was calculated (time spent exploring the novel object divided by the total time spent exploring the objects). Total object exploration times in the sample-phase and object-biases were also calculated.

\section{Data analyses and statistics}

Analyses were done using SPSS (v21.0, IBM Corp, Armonk, NY). Auditory-evoked neural responses were analysed using one-way between-subjects ANOVAs. Gabazine effect on pyramidal neuron firing was analysed with two-way ANOVA (with treatment and genotype as main factors). The behavioural data was analysed with repeated measured ANOVAs. Significant interactions were followed by one-way ANOVAs or Newman-Keuls post hoc comparisons.

\section{Results}

\section{Experiment 1: baseline discharge rates}

See Supplementary Figure 1a for waveform features used to classify units as putative pyramidal cells or putative fastspiking interneurons. Df(h15q13/+) mice showed decreased baseline PrL interneuron discharge rate (Fig. 1a; $F_{1,94}=8.58$, $p=0.004)$. There was no effect of genotype on baseline pyramidal neuron discharge rate $\left(F_{1,334}=1.71, p=0.191\right)$.

\section{Experiment 2: cortical auditory-evoked neuron response}

In the double-click paradigm (Fig. 1b-d), decreased neuron firing was observed in $\mathrm{D}(\mathrm{h} 15 \mathrm{q} 13 /+)$ interneurons (Fig. 1b; $F_{1}$, $\left.{ }_{70}=6.74, p=0.011\right)$ but not pyramidal neurons $\left(F_{1,239}=1.40\right.$, $p=0.238) . \operatorname{Df}(\mathrm{h} 15 \mathrm{q} 13 /+)$ interneurons $\left(F_{1,43}=6.64\right.$, $p=0.013)$ and pyramidal cells $\left(F_{1,146}=8.82, p=0.003\right)$ also had increased onset latencies (Fig. 1c).

\section{Experiment 3: intra-mPFC GABA $A_{\mathbf{A}} R$ antagonism and pyramidal discharge rate}

See Supplementary Figure $1 \mathrm{~b}$ for average action potential durations of cells classified as pyramidal cells. The $\mathrm{Df}(\mathrm{h} 15 \mathrm{q} 13 /+$ ) mutant showed decreased pyramidal neuron response to intra-mPFC $\mathrm{GABA}_{\mathrm{A}} \mathrm{R}$ antagonism (Fig. 1e). A two-way ANOVA revealed significant main effects of gabazine $\left(F_{1}\right.$, $115=14.63, p=0.0002 ; \mathrm{Ns}=53$ and 66 for saline and gabazine, respectively), and genotype $\left(F_{1,115}=12.02\right.$, $p=0.0007 ; \mathrm{Ns}=67$ and 52 for $\mathrm{WT}$ and $\mathrm{TG}$, respectively) and a significant gabazine $\times$ genotype interaction $\left(F_{1}\right.$, $115=6.23, p=0.020$ ). Post hoc analysis (Newman-Keuls) revealed a significant difference in firing rates between gabazine and standard recording conditions in WT mice $(0.97 \pm 0.26 \mathrm{vs}$. $3.58 \pm 0.59$ spikes/s, $n=29$ and 38 , respectively; $p<0.00002$ ) but not in $\operatorname{Df}(\mathrm{h} 15 \mathrm{q} 13 /+)$ mice $(0.57 \pm 0.16$ vs. $1.12 \pm 0.10$ spikes/s; $n=24$ and 28, respectively) (Fig. 1e). Hence, gabazine markedly elevated the discharge of putative pyramidal neurons in the PFC of WT mice, as previously observed in rats (Lladó-Pelfort et al. 2012) but not in $\mathrm{Df}(\mathrm{h} 15 \mathrm{q} 13 /+)$ mice. This suggests that the $\mathrm{Df}(\mathrm{h} 15 \mathrm{q} 13 /+)$ mouse has altered inhibitory neurotransmission in this cortical area.

\section{Experiments 4-6: the touchscreen 5-CSRTT}

$\operatorname{Df}(\mathrm{h} 15 \mathrm{q} 13 /+)$ mice showed a selective stimulus durationdependent accuracy deficit following extended training (Fig. 2a-d). When manipulating the stimulus duration, there were no effects of genotype or genotype by stimulus duration interactions on initial tests using 40- or 80-trial session lengths (Supplementary Fig. 2a-c). However, reproducible stimulus duration-dependent impairments were observed following extended training ( 100 sessions) using 140 trials per session. Extended training improved the performance of WT animals thereby producing increased room to detect the performance decrement of the $\operatorname{Df}(\mathrm{h} 15 \mathrm{q} 13) /+$ mice (see Supplementary Fig. 2a-c).

When tested on 140 trials per session, the $\operatorname{Df}(\mathrm{h} 15 \mathrm{q} 13 /+)$ mice showed decreased accuracies at shorter SDs (Fig. 2a, genotype: $F_{1,29}=11.08, p=0.002$, genotype $\times \mathrm{SD}: F_{3}$, $\left.{ }_{87}=5.92, p=0.001\right)$. The $\mathrm{Df}(\mathrm{h} 15 \mathrm{q} 13 /+)$ mouse showed lower accuracies at the 0.8 -s $(p=0.001)$ and 0.6 -s SDs $(p=0.002)$ but not at the 1-s $(p=0.074)$ and 2-s SDs $(p=0.375)$. There were no effects of genotype or genotype $\times$ SD interaction on percent omission (Fig. 2b) or any other behavioural measure ( $p \geq 0.20$; Supplementary Table S1). The accuracy impairment in the $\mathrm{Df}(\mathrm{h} 15 \mathrm{q} 13 /+)$ was reproduced in the same cohort of animals using stimulus durations between 2 and $0.2 \mathrm{~s}$ (Fig. 2c, d). Trial-bin analyses showed that $\mathrm{Df}(\mathrm{h} 15 \mathrm{q} 13 /+)$ mice had impaired accuracy throughout the length of the sessions. Thus, the deficit was not related to impaired vigilance (Supplementary Fig. 2a-c). No impairment was observed on 
Fig. 2 Performance of Df (h15q13)/+ and WT littermates in the 5-choice serial reaction time task. Data are presented as means \pm SEM. a-b Test 1 - decreasing stimulus durations. The Df (h15q13)/+ mouse showed lower accuracies at shorter stimulus durations (a) but did not differ from WTs on percent omission (b). c-d Test 2-decreasing stimulus durations. The accuracy impairment in the Df(h15q13)/+ mouse was reproduced using stimulus durations between 2 and $0.2 \mathrm{~s}(\mathbf{c})$. There was again no effect of genotype on percent omission (d). Asterisks denote $p<0.05(* p<0.05, * * p<0.01)$
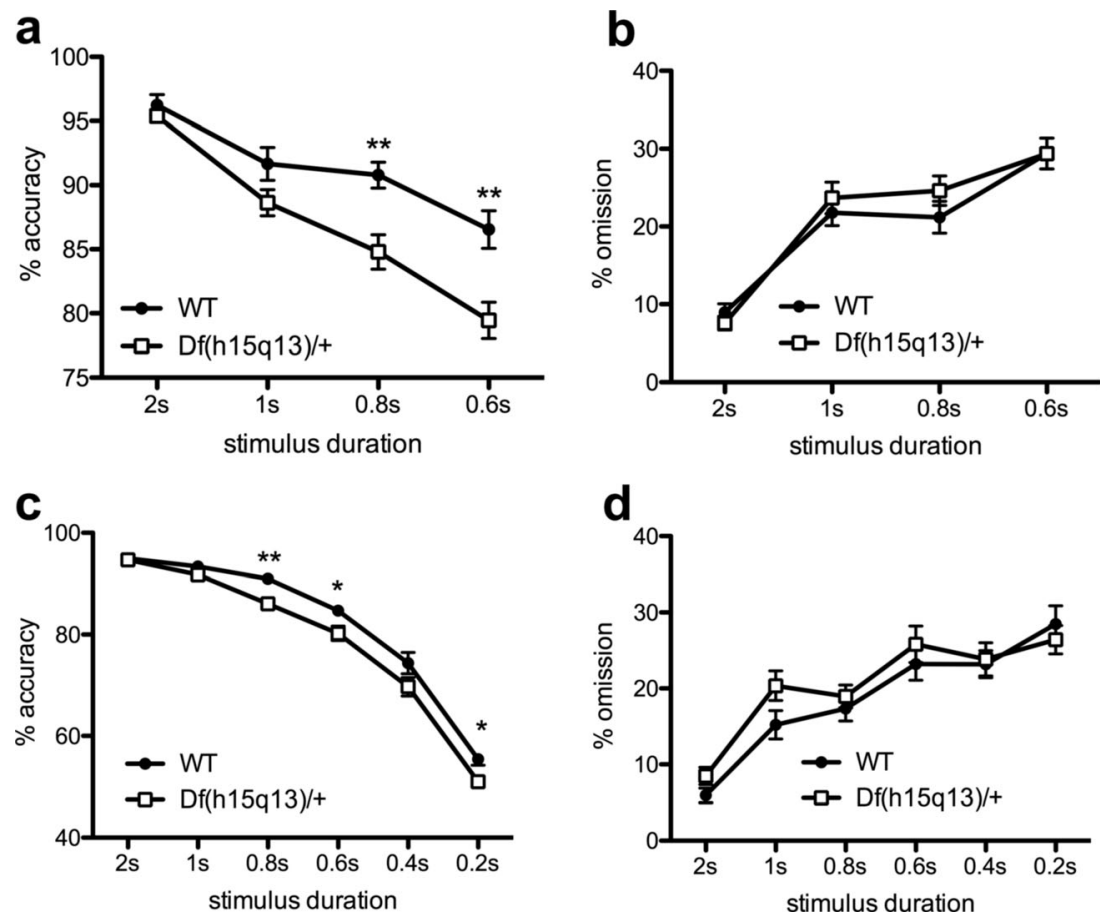

test of increasing delays measuring impulsive responding (Supplementary Fig. $3 \mathrm{~d}$ ) and the partial $\alpha_{7} \mathrm{nAChR}$ agonist EVP-6124 did not reverse the accuracy impairment in the Df(h15q13/+) mouse (Table 1).

\section{Experiments 7-12: additional cognitive}

\section{Experiment 7-visual discrimination and reversal learn-} ing There was no effect of genotype on visual discrimination learning (Supplementary Fig. S3a-b; $p \geq 0.441$ ) or reversal learning (Fig. 3a, b; $p \geq 0.080$ ).

Experiment 8-paired-associate learning (PAL) There was no significant effect of genotype in the PAL task. There was no effect of genotype or genotype $\times$ session interaction on percent accuracy (Fig. 3c; $p \geq 0.103$ ) or correction trials (Supplementary Fig. 3c; $p \geq 0.061$ ).
Experiment 9-progressive ratio (PR) Genotype did not affect measures of motivation in the PR task. There was no effect of genotype or genotype $\times$ PR schedule interaction on trials completed (Fig. $3 \mathrm{~d} ; p \geq 0.321$ ) or break points (Supplementary Fig. 3e; $p \geq 0.321$ ).

Experiment 10 - extinction learning There were no effect of genotype or genotype $\times$ session interaction on percent responses in extinction learning (Fig $3 \mathrm{e} ; p \geq 0.385$ ).

Experiment 11-trial-unique non-match to sample When tested on increasing delays, there was no effect of genotype or genotype $\times$ delay interaction on percent accuracy (Fig. 3e; $p \geq 0.692$ ). Similarly, there was no effect of genotype or genotype $\times$ separation interaction when tested using increasing stimuli separations (Fig. 3e; $p \geq 0.692$ ). There
Table 1 Effect of systemic EVP6124 on 5-CSRTT performance in WT and $\mathrm{Df}(\mathrm{h} 15 \mathrm{q} 13) /+$ mice

\begin{tabular}{lllll}
\hline & $\%$ accuracy & & \multicolumn{3}{c}{$\%$ omission } \\
\hline Dose $(\mathrm{mg} / \mathrm{kg})$ & $\mathrm{WT}$ & $\mathrm{Df}(\mathrm{h} 15 \mathrm{q} 13) /+$ & $\mathrm{WT}$ & $\mathrm{Df}(\mathrm{h} 15 \mathrm{q} 13) /+$ \\
0 & $90.45 \pm 1.06$ & $85.55 \pm 1.46$ & $13.24 \pm 1.96$ & $17.07 \pm 1.90$ \\
1 & $90.14 \pm 0.91$ & $86.84 \pm 1.25$ & $13.77 \pm 2.29$ & $17.08 \pm 1.96$ \\
10 & $90.06 \pm 1.14$ & $83.70 \pm 2.02$ & $14.95 \pm 1.58$ & $20.33 \pm 3.36$ \\
30 & $87.38 \pm 1.07$ & $85.02 \pm 1.41$ & $20.88 \pm 2.55$ & $22.15 \pm 2.77$ \\
\hline
\end{tabular}

Animals were tested using a 140-trial session length, 5-s delay, and 0.8-s SD. No effect of EVP-6124 on percent accuracy (genotype: $F_{1,30}=8.96, p=0.004$, dose: $F_{3,90}=2.12, p=0.104$, dose $\times$ genotype: $F_{3,90}=1.51$, $p=0.216$ ). EVP-6124 increased omissions at highest dose relative to vehicle (genotype: $F_{1,30}=1.97, p=0.171$, dose: $F_{3,90}=5.10, p=0.003$, dose $\times$ genotype: $\left.F_{3,90}=0.43, p=0.735\right)$ in both $\mathrm{Df}(\mathrm{h} 15 \mathrm{q} 13) /+$ and WT animals 
a

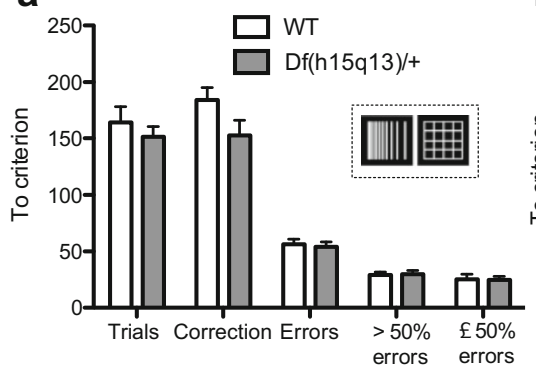

e

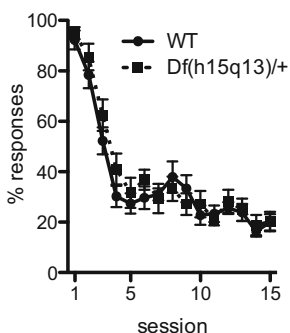

b

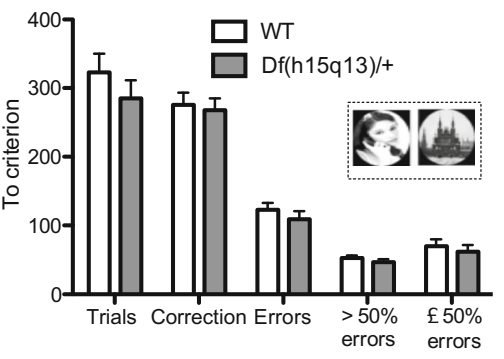

C

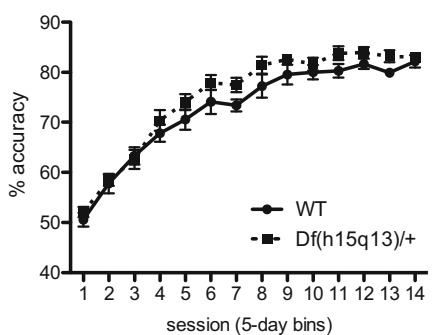

d

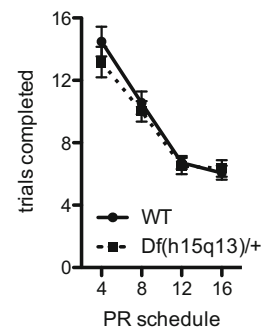

f

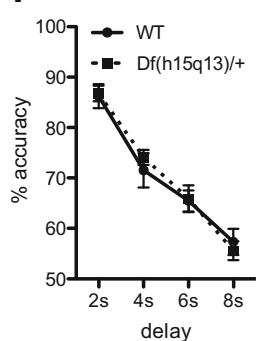

g

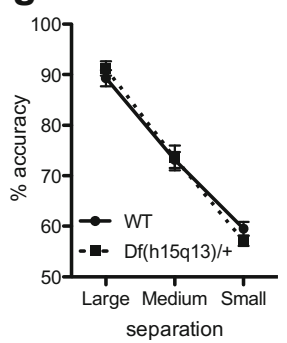

h

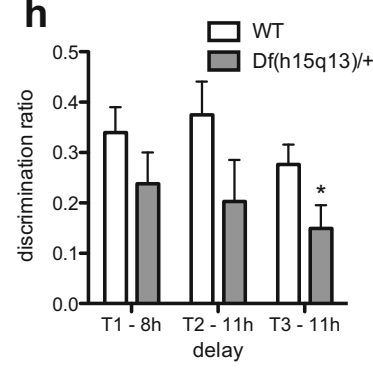

i

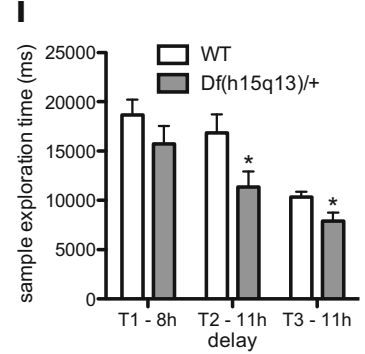

Fig. 3 Performance of $\mathrm{Df}(\mathrm{h} 15 \mathrm{q} 13) /+$ and WT littermates on tests of cognitive flexibility, working memory, motivation and learning and memory. a Reversal learning test 1 - “easy" discriminable stimuli. Inset depicts the stimuli. No effect of genotype on trials to criterion, correction trials to criterion, errors to criterion, early errors, or late errors $(p \geq 0.080)$. b Reversal learning test 2- "challenging" stimuli. No effect of genotype on trials to criterion, correction trials to criterion, errors to criterion, early errors, or late errors $(p \geq 0.277)$. c Paired-associate learning (PAL). No effect of genotype on percent accuracy $(p \geq 0.103)$. d Progressive ratio.
No effect of genotype on trials completed ( $p \geq 0.321)$. e Extinction learning. No effect of genotype on percent responses $(p \geq 0.385)$. f TUNL - delay challenge. No effect of genotype on percent accuracy $(p \geq 0.692)$. g TUNL - pattern separation challenge. No effect of genotype on percent accuracy $(p \geq 0.302)$. $\mathbf{h}-\mathbf{i}$ Novel object recognition. The $\mathrm{Df}(\mathrm{h} 15 \mathrm{q} 13 /+)$ mouse showed reduced discrimination ratio at the 11-h delay (trial 2: $p=0.12$, trial 3: $p=0.047$ ) and reduced sample exploration time at the 11-h delay (trial 2: $p=.036$; trial 3: $p=0.023)$. Asterisks denote differences at which $p<0.05\left({ }^{*} p<0.05\right)$ were no effects of genotype on correction trials to criterion in either test (Supplementary Fig. 4f, g; $p \geq 0.683$ ).

\section{Experiment 12-novel object recognition (NOR) The} $\mathrm{Df}(\mathrm{h} 15 \mathrm{q} 13 /+)$ mouse showed impaired novel object recognition (Fig. 3h). However, this impairment was coupled with deceased sample exploration times (Fig. 3i) and can therefore not confidently be ascribed to a memory impairment. At the 8$\mathrm{h}$ delay, there was no effect of genotype on sample exploration time or discrimination ratio $(p \geq 0.225)$. At the 11-h delay, the $\operatorname{Df}(\mathrm{h} 15 \mathrm{q} 13 /+)$ mouse showed decreased discrimination ratios (trial 2: $p=0.120$; trial 3: $p=0.047$ ) and decreased sample exploration times (trial 2: $p=.036$; trial 3: $p=0.023$ ).

\section{Discussion}

A chromosomal microdeletion at locus $15 \mathrm{q} 13.3$ is one of the largest known risk factors of schizophrenia and represents an ideal opportunity for back-translational study. We have previously generated a mouse model of the 15q13.3 microdeletion $(\operatorname{Df}(\mathrm{h} 15 \mathrm{q} 13) /+)$ (Fejgin et al. 2014), and here, we characterised it using a variety of neurophysiological, pharmacological, and behavioural assays across multiple experimental sites. This comprehensive phenotyping revealed marked medial prefrontal cortical dysfunctions in the $\mathrm{Df}(\mathrm{h} 15 \mathrm{q} 13) /+$ model as measured by multiple parallel tests of inhibitory transmission and attentional functioning. These dysfunctions were observed as decreased baseline activity of putative interneuron and reduced interneuron and pyramidal neuron sensitivity to auditory stimulation. The $\mathrm{Df}(\mathrm{h} 15 \mathrm{q} 13) /+$ mouse also showed reduced sensitivity to intra-mPFC $\mathrm{GABA}_{\mathrm{A}} \mathrm{R}$ blockade as measured by pyramidal neuron spike frequencies and a selective attentional impairment in the prefrontal cortical-dependent 5-CSRTT. Furthermore, we show that the attentional impairment of the $\mathrm{Df}(\mathrm{h} 15 \mathrm{q} 13) /+$ mouse is insensitive to systemic treatment with the partial $\alpha_{7} \mathrm{nAChR}$ agonist EVP-6124.

The $\operatorname{Df}(\mathrm{h} 15 \mathrm{q} 13) /+$ mouse showed reduced putative fast-spiking interneuron baseline activity and decreased putative pyramidal cell and fast-spiking interneuron auditory-evoked responses. These dysfunctions have clear translational relevance to schizophrenia and attentional dysfunction. For example, schizophrenia is associated with neurophysiological dysfunctions in passive sensory stimulation paradigms (2012) such as pre-attentative measures of mismatch negativity and repetition positivity (Baldeweg et al. 2004) and N100 amplitudes (Michie et al. 1990) as well as suppressed P50 gating (Adler et al. 1982), a phenomenon involving $\alpha_{7} \mathrm{nAChRs}$ (Freedman et al. 1997) coded by the 
CHRNA7 gene for which the $\operatorname{Df}(\mathrm{h} 15 \mathrm{q} 13) /+$ mouse shows allelic insufficiency (Fejgin et al. 2014). Information processing deficits also include attenuated attentional allocation-driven cortical event-related potential P3b amplitudes (Roxborough et al. 1993; Weisbrod et al. 1999; Ford et al. 2001) and increased latencies of evoked potentials in visual and auditory paradigms, such as continuous performance tasks (Nieman et al. 2002) that reflect disrupted GABAergic (Benes and Berretta 2001) and cholinergic (Baldeweg et al. 2006) signalling efficacy. Reduction in cortical inhibition as measured by transcranial magnetic stimulation has also been observed in schizophrenic patients independent of clinical state (Fitzgerald et al. 2002; Daskalakis et al. 2002; Wobrock et al. 2008; Liu et al. 2009), and the phenotype is similarly linked to deficient cortical GABAergic transmission and attentional processes (Daskalakis et al. 2007). Analogous cortical neurophysiological dysfunction of auditory and visual event-related responses is also found in pharmacological animal models of schizophrenia (Bickel and Javitt 2009). Thus, our data indicate that the $\operatorname{Df}(\mathrm{h} 15 \mathrm{q} 13) /+$ mouse has decreased speed of processing and reduced recruitment of putative fast-spiking interneurons in the PrL and this phenotype corresponds with observations in schizophrenia patients. This also parallels our previous observations of reduced parietal, prelimbic, and hippocampal oscillatory activity or auditory-evoked potentials in the Df(h15q13)/+ mouse (Fejgin et al. 2014) which in conjunction with the current data would suggest more systemic speed of processing deficits in the mutant.

The Df(h15q13)/+ mouse showed prefrontal cortical $\mathrm{GABA}_{\mathrm{A}} \mathrm{R}$ antagonist hyposensitivity with attenuated increase of putative pyramidal spike frequency in response to local (PrL + anterior cingulate) application of the $\mathrm{GABA}_{\mathrm{A}} \mathrm{R}$ antagonist gabazine. The data parallel findings of disrupted GABAergic activity in many schizophrenia-relevant animal models, including cortical reductions in GABA-related markers (Morrow et al. 2007; Lodge et al. 2009; Francois et al. 2009; Ammassari-Teule et al. 2009) and aberrant pharmacological activation of fast-spiking interneurons (Tseng et al. 2008). The decreased sensitivity to $P F C G_{B B A} R$ blockade in $\mathrm{Df}(\mathrm{h} 15 \mathrm{q} 13) /+$ mice is also in agreement with histological findings in patients with schizophrenia showing reduced cortical expressions in a range of GABAergic markers, including non-pyramidal cells (1991), PV-immunoreactivity (Beasley and Reynolds 1997), GAD65/67 levels (Akbarian et al. 1995), and GAT1 (Volk et al. 2001). In sum, the attenuated putative pyramidal response to local $\mathrm{GABA}_{\mathrm{A}} \mathrm{R}$ blockade in the $\operatorname{Df}(\mathrm{h} 15 \mathrm{q} 13) /+$ mice is in general agreement with data showing decreased GABAergic function in schizophrenia patients. The phenotype is also in agreement with the $\mathrm{GABA}_{\mathrm{A}} \mathrm{R}$ antagonist hyposensitivity of $\mathrm{Df}(\mathrm{h} 15 \mathrm{q} 13) /+$ in seizure assays (Fejgin et al. 2014) and the decreased speed of processing and reduced baseline firing and decreased recruitment of putative fast-spiking interneurons in response to auditory stimulation.
We have seen no marked reduction of GABAergic markers that can account for the observed attenuation of putative interneuron basal activity or the decreased sensitivity of putative interneuron to auditory stimulation and pyramidal neuron sensitivity to $\mathrm{GABA}_{\mathrm{A}} \mathrm{R}$ antagonism in the $\mathrm{Df}(\mathrm{h} 15 \mathrm{q} 13) /+$ mouse. In situ hybridization studies have nevertheless revealed a small but significant difference in prefrontal GAD expression in the Df(h15q13)/+ mutant $(\leq 10 \%$; N. Santana, F. Artigas, unpublished observations). Notably, disruption of numerous transmitter processes affect cortical inhibitory control and pyramidal neuron sensitivity to GABAergic drugs (Haenschel and Linden 2001; Javitt et al. 2008; Kjaerby et al. 2014) and further work will be required to determine more fully the mechanisms underpinning the prefrontal cortical phenotype of the $\operatorname{Df}(\mathrm{h} 15 \mathrm{q} 13) /+$ mouse.

Importantly, the $\mathrm{Df}(\mathrm{h} 15 \mathrm{q} 13) /+$ mouse also exhibited a selective impairment in accuracy at shorter stimulus durations in the 5-CSRTT. This impairment was found after repeated testing improved the performance of WT animals which unmasked the deficit in the $\operatorname{Df}(\mathrm{h} 15 \mathrm{q} 13) /+$ mouse. The impairment was always observed throughout the sessions and therefore not related to reduced vigilance (see Supplementary Fig. S2a-c). Percent accuracy is considered a primary marker of attentional control in the 5-CSRTT. Percent omission and latency measures, which can reflect motivational, sensory, or motoric factors (Robbins 2002), were unaffected in the Df(h15q13)/+ mouse. The accuracy impairment was also only observed at shorter stimulus duration, further indicating that the phenotype is produced by impaired attention.

Attentional dysfunction is at the core of the cognitive deficits of schizophrenia (Marder and Fenton 2004; Carter and Barch 2007); it can precede other symptoms (Cornblatt et al. 1999), predict disorder development (2001), and be present in non-affected first-degree relatives (Snitz et al. 2006). Thus, the observation of similar attentional deficits in the $\mathrm{Df}(\mathrm{h} 15 \mathrm{q} 13) /+$ mouse suggests that the model carries translational utility within this cognitive domain with possible relevance for drug discovery.

An attentional impairment in the 5-CSRTT can also be predicted by the prelimbic neurophysiological and GABAergic phenotypes of the $\operatorname{Df}(\mathrm{h} 15 \mathrm{q} 13) /+$ mouse. In animals, intra-mPFC administration of $\mathrm{GABA}_{\mathrm{A}} \mathrm{R}$ antagonists (Paine et al. 2011; Pehrson et al. 2013; Pezze et al. 2014) and agonists (Paine et al. 2011; Pezze et al. 2014) decrease percent accuracy in the 5-CSRTT, indicating that imbalances in cortical inhibitory activity disrupts attention. Moreover, in a variation of the 5-CSRTT, attenuated PrL inhibitory activity can predict accuracy while being unrelated to errors of omissions and premature responding (Totah et al. 2009). Our observations of attenuated PrL inhibitory activity together with a selective accuracy impairment in the $\operatorname{Df}(\mathrm{h} 15 \mathrm{q} 13) /+$ mice are entirely consistent with this view. 
However, Df(h15q13)/+ and WT animals did not differ in performance on tasks dependent on cognitive flexibility, working memory, visuospatial learning, and motivation. The current behavioural experiments employed a battery approach where some animals where tested sequentially on multiple touchscreen tasks, and it may be that response strategies acquired in previous assays proactively interfered with performance on later tasks thereby masking more general effects of genotype on cognition. This is however unlikely.

First, the $\operatorname{Df}(\mathrm{h} 15 \mathrm{q} 13) /+$ mouse has previously been shown to exhibit a mild cognitive phenotype; the deletion fails to affect associative learning, spatial working memory, and sensorimotor gating (Fejgin et al. 2014). Visual discrimination and reversal learning, spatial working memory, and fear conditioning were also recently found to be unaffected in an alternative mouse model of the 15q13.3DS (D/+) (Kogan et al. 2015). Our observation of normal working memory, discrimination learning, and cognitive flexibility in the $\mathrm{Df}(\mathrm{h} 15 \mathrm{q} 13) /+$ mutant is in comprehensive agreement with these reports. Furthermore, reproducible attentional impairments were observed following extended testing in the 5-CSRTT. If extended testing masks some cognitive phenotypes in the $\mathrm{Df}(\mathrm{h} 15 \mathrm{q} 13) /+$ mutant the opposite pattern should be expected, deficits should be attenuated with repeated testing and not remain stable across multiple tests.

Moreover, although cortical GABAergic activity is relevant for a wide range of cognitive domains, $\mathrm{MPFC}$-specific $\mathrm{GABA}_{\mathrm{A}} \mathrm{R}$ antagonism through bicucilline fails to affect reversal learning (Enomoto et al. 2011) and working memory as assessed in the radial-arm maze (Enomoto et al. 2011) and Tmaze (Herremans et al. 1996). Attentional function therefore appears particularly sensitive to GABAergic disruption (Enomoto et al. 2011; Tse et al. 2015). Nevertheless, under the present conditions, the lack of comprehensive impairment in these assays may limit the behavioural translational potential of the $\operatorname{Df}(\mathrm{h} 15 \mathrm{q} 13) /+$ mouse to attentional dysfunction.

Reduced $\alpha_{7} \mathrm{nAChR}$ expression has been advanced as a possible mechanism underlying the neuropsychiatric phenotypes of 15q13.3DS (LePichon et al. 2010; Hoppman-Chaney et al. 2013), and decreased cortical $\alpha_{7} \mathrm{nAChR}$-expression is a mechanistic candidate for the $\operatorname{Df}(\mathrm{h} 15 \mathrm{q} 13) /+$ phenotype. $\alpha_{7}$ nAChRs are expressed in parvalbumin-positive GABAergic fast-spiking interneurons (Murakami et al. 2013), Chrna7 deletion causes dysregulated cortical inhibitory activity (Adams et al. 2012; Lin et al. 2014), and Chrna $7^{-1-}$ mice show retarded performance in the 5-CSRTT (Young et al. 2004; Hoyle et al. 2006; Young et al. 2007).

However, acute dosing with the partial $\alpha_{7} \mathrm{nAChR}$ agonist EVP-6124 did not attenuate the attentional deficit in $\operatorname{Df}(\mathrm{h} 15 \mathrm{q} 13) /+$ mice. The lack of acute effect may be explained by reduced cortical $\alpha_{7} \mathrm{nAChR}$ expression leading to insufficient number of channels to be activated (full agonist treatment or chronic dosing may be required for efficacy) or by rapid agonist-induced receptor desensitisation leading to functional inactivation of the $\alpha_{7} \mathrm{nAChR}$ at the EVP-6124 doses used. Nevertheless, $\alpha_{7} \mathrm{nAChR}$ agonists have often failed to affect attentional measures in schizophrenic patients (Olincy et al. 2006; Freedman et al. 2008; Lieberman et al. 2013; Preskorn et al. 2014; Umbricht et al. 2014) and rodent 5CSRTT performance (Grottick et al. 2003; Hahn et al. 2003; Hoyle et al. 2006). In accordance with this, we found EVP6124 to be ineffective against the attentional impairment in the $\operatorname{Df}(\mathrm{h} 15 \mathrm{q} 13) /+$ mice. Thus, although decreased $\alpha_{7} \mathrm{nAChR}$ expression may cause cortical neurophysiological and attentional deficits, data indicate that $\alpha_{7} \mathrm{nAChR}$ agonism does not produce sufficient efficacy or that the mechanism underlying the phenotype may be downstream from the $\alpha_{7} \mathrm{nAChR}$ receptor or due to the functional importance of the deletion of other genes in the $\mathrm{CNV}$ region (Fejgin et al. 2014).

In sum, we observed multiple dysfunctions converging on disrupted medial prefrontal cortical functioning in the $\operatorname{Df}(\mathrm{h} 15 \mathrm{q} 13) /+$ mouse. These dysfunctions were observed as (i) decreased baseline firing and attenuated auditory-evoked responses of putative inhibitory interneurons and (ii) reduced putative pyramidal cell sensitivity to local $\mathrm{GABA}_{\mathrm{A}} \mathrm{R}$ antagonism and (iii) selective decrease in percent accuracy in the 5CSRTT. These data parallel the phenotypes of 15q13.3DSrelated neuropsychiatric disorders and indicate that the $\operatorname{Df}(\mathrm{h} 15 \mathrm{q} 13) /+$ mouse has translational relevance for modelling some cortical dysfunctions associated with schizophrenia.

Acknowledgments The research leading to these results has received support from the Innovative Medicine Initiative Joint Undertaking under grant agreement no. 115008 of which resources are composed of EFPIA in-kind contribution and financial contribution from the European Union's Seventh Framework Programme (FP7/2007-2013). The Behavioural and Clinical Neuroscience Institute is co-funded by the Medical Research Council and the Wellcome Trust. This study was also supported by the Instituto de Salud Carlos III, Centro de Investigación Biomédica en Red de Salud Mental (CIBERSAM). The authors would like to thank Mercedes Nuñez, Noemí Jurado, Edita Bulovaite, Sueda Tunçak, Lewis Buss, and Diab Ali for the skillful technical assistance.

Open Access This article is distributed under the terms of the Creative Commons Attribution 4.0 International License (http:// creativecommons.org/licenses/by/4.0/), which permits unrestricted use, distribution, and reproduction in any medium, provided you give appropriate credit to the original author(s) and the source, provide a link to the Creative Commons license, and indicate if changes were made.

\section{References}

Adams CE, Yonchek JC, Schulz KM et al (2012) Reduced Chrna7 expression in mice is associated with decreases in hippocampal markers of inhibitory function: implications for neuropsychiatric diseases. Neuroscience 207:274-282. doi:10.1016/j.neuroscience.2012.01.033 
Adler LE, Pachtman E, Franks RD et al (1982) Neurophysiological evidence for a defect in neuronal mechanisms involved in sensory gating in schizophrenia. Biol Psychiat 17:639-654

Adler LE, Olincy A, Waldo M et al (1998) Schizophrenia, sensory gating, and nicotinic receptors. Schizophr Bull 24:189-202

Akbarian S, Kim JJ, Potkin SG et al (1995) Gene expression for glutamic acid decarboxylase is reduced without loss of neurons in prefrontal cortex of schizophrenics. Arch Gen Psychiat 52:258-266

Ammassari-Teule M, Sgobio C, Biamonte F et al (2009) Reelin haploinsufficiency reduces the density of $\mathrm{PV}+$ neurons in circumscribed regions of the striatum and selectively alters striatalbased behaviors. Psychopharmacology 204:511-521. doi:10.1007/ s00213-009-1483-x

Baldeweg T, Klugman A, Gruzelier J, Hirsch SR (2004) Mismatch negativity potentials and cognitive impairment in schizophrenia. Schizophrn Res 69:203-217. doi:10.1016/j.schres.2003.09.009

Baldeweg T, Wong D, Stephan KE (2006) Nicotinic modulation of human auditory sensory memory: evidence from mismatch negativity potentials. Int J Psychophysiol 59:49-58. doi:10.1016/j.ijpsycho. 2005.07.014

Barthó P, Hirase H, Monconduit L et al (2004) Characterization of neocortical principal cells and interneurons by network interactions and extracellular features. J Neurophysiol 92:600-608. doi:10.1152/jn. 01170.2003

Beasley CL, Reynolds GP (1997) Parvalbumin-immunoreactive neurons are reduced in the prefrontal cortex of schizophrenics. Schizophrn Res 24:349-355

Benes FM, Berretta S (2001) GABAergic interneurons: implications for understanding schizophrenia and bipolar disorder. Neuropsychopharmacol 25:1-27. doi:10.1016/S0893-133X(01)00225-1

Ben-Shachar S, Lanpher B, German JR et al (2009) Microdeletion 15q13.3: a locus with incomplete penetrance for autism, mental retardation, and psychiatric disorders. J Med Genet 46:382-388. doi:10.1136/jmg.2008.064378

Bickel S, Javitt DC (2009) Neurophysiological and neurochemical animal models of schizophrenia: focus on glutamate. Behav Brain Res 204:352-362. doi:10.1016/j.bbr.2009.05.005

Carter CS, Barch DM (2007) Cognitive neuroscience-based approaches to measuring and improving treatment effects on cognition in schizophrenia: the CNTRICS initiative. Schizophr Bull 33:11311137. doi: $10.1093 / \mathrm{schbul} / \mathrm{sbm} 081$

Chudasama Y, Muir JL (2001) Visual attention in the rat: a role for the prelimbic cortex and thalamic nuclei? Behav Neurosci 115:417-428

Cornblatt B, Obuchowski M, Roberts S et al (1999) Cognitive and behavioral precursors of schizophrenia. Dev Psychopathol 11:487-508

Daskalakis ZJ, Christensen BK, Chen R et al (2002) Evidence for impaired cortical inhibition in schizophrenia using transcranial magnetic stimulation. Arch Gen Psychiat 59:347-354

Daskalakis ZJ, Fitzgerald PB, Christensen BK (2007) The role of cortical inhibition in the pathophysiology and treatment of schizophrenia. Brain Res Rev 56:427-442. doi:10.1016/j.brainresrev.2007.09.006

Debarbieux F, Brunton J, Charpak S (1998) Effect of bicuculline on thalamic activity: a direct blockade of IAHP in reticularis neurons. J Neurophysiol 79:2911-2918

Enomoto T, Tse MT, Floresco SB (2011) Reducing prefrontal gammaaminobutyric acid activity induces cognitive, behavioral, and dopaminergic abnormalities that resemble schizophrenia. Biol Psychiat 69:432-441. doi:10.1016/j.biopsych.2010.09.038

Fejgin K, Nielsen J, Birknow MR et al (2014) A mouse model that recapitulates cardinal features of the $15 \mathrm{q} 13.3$ microdeletion syndrome including schizophrenia- and epilepsy-related alterations. Biol Psychiat 76:128-137. doi:10.1016/j.biopsych.2013.08.014

Fitzgerald PB, Brown TL, Daskalakis ZJ, Kulkarni J (2002) A transcranial magnetic stimulation study of inhibitory deficits in the motor cortex in patients with schizophrenia. Psychiat Res 114:11-22
Ford JM, Mathalon DH, Kalba S et al (2001) N1 and P300 abnormalities in patients with schizophrenia, epilepsy, and epilepsy with schizophrenialike features. Biol Psychiat 49:848-860. doi:10. 1016/S0006-3223(00)01051-9

Francois J, Ferrandon A, Koning E et al (2009) Selective reorganization of GABAergic transmission in neonatal ventral hippocampallesioned rats. Int J Neuropsychopharm 12:1097. doi:10.1017/ S1461145709009985

Freedman R, Coon H, Myles-Worsley M et al (1997) Linkage of a neurophysiological deficit in schizophrenia to a chromosome 15 locus. Proc Natl Acad Sci U S A 94:587-592. doi:10.2307/41247

Freedman R, Olincy A, Buchanan RW et al (2008) Initial phase 2 trial of a nicotinic agonist in schizophrenia. Am J Psychiatry 165:1040-1047. doi:10.1176/appi.ajp.2008.07071135

Garay RP, Citrome L, Samalin L et al (2016) Therapeutic improvements expected in the near future for schizophrenia and schizoaffective disorder: an appraisal of phase III clinical trials of schizophreniatargeted therapies as found in US and EU clinical trial registries. Expert Opin Pharmacother. doi:10.1517/14656566.2016.1149164

Gillentine MA, Schaaf CP (2015) The human clinical phenotypes of altered CHRNA7 copy number. Biochem Pharmacol 97:352-362. doi:10.1016/j.bcp.2015.06.012

Grottick AJ, Haman M, Wyler R, Higgins GA (2003) Reversal of a vigilance decrement in the aged rat by subtype-selective nicotinic ligands. Neuropsychopharmacol 28:880-887. doi:10.1038/sj.npp. 1300102

Haenschel C, Linden D (2001) Neurophysiology of cognitive dysfunction in schizophrenia. In: Ritsner MS (ed) Handbook of schizophrenia spectrum disorders: phenotypic and endophenotypic presentations. Springer, pp 449-480

Hahn B, Sharples CGV, Wonnacott S et al (2003) Attentional effects of nicotinic agonists in rats. Neuropharmacology 44:1054-1067. doi: 10.1016/S0028-3908(03)00099-6

Hajos M, Hurst RS, Hoffmann WE et al (2005) The selective alpha7 nicotinic acetylcholine receptor agonist PNU-282987 [N-[(3R)-1Azabicyclo[2.2.2]oct-3-yl]-4-chlorobenzamide hydrochloride] enhances GABAergic synaptic activity in brain slices and restores auditory gating deficits in anesthetized rats. J Pharmacol Exp Ther 312:1213-1222. doi:10.1124/jpet.104.076968

Heath CJ, Bussey TJ, Saksida LM (2015) Motivational assessment of mice using the touchscreen operant testing system: effects of dopaminergic drugs. Psychopharmacology 1-15. doi: 10.1007/s00213015-4009-8

Helbig I, Mefford HC, Sharp AJ, Guipponi M, Fichera M, Franke A, Muhle H, de Kovel C, Baker C, von Spiczak S, Kron KL, Steinich I, zlig-Lie AAK, Leu C, Gaus V, Schmitz B, Klein KM, Reif PS, Rosenow F, Weber Y, Lerche H, Zimprich F, Urak L, Fuchs K, Feucht M, Genton P, Thomas P, Visscher F, de Haan GJ, Møller RS, Hjalgrim H, Luciano D, Wittig M, Nothnagel M, Elger CE, Nürnberg P, Romano C, Malafosse A, Koeleman BPC, Lindhout D, Stephani U, Schreiber S, Eichler EE, Sander T (2009) 15q13.3 microdeletions increase risk of idiopathic generalized epilepsy. Nat Genet 41:160-162. doi:10.1038/ng.292

Herremans AH, Hijzen TH, Welborn PF et al (1996) Effects of infusion of cholinergic drugs into the prefrontal cortex area on delayed matching to position performance in the rat. Brain Res 711:102-111

Hoppman-Chaney N, Wain K, Seger PR et al (2013) Identification of single gene deletions at 15q13.3: further evidence that CHRNA7 causes the $15 \mathrm{q} 13.3$ microdeletion syndrome phenotype. Clin Genet 83:345-351. doi:10.1111/j.1399-0004.2012.01925.x

Horner AE, Heath CJ, Hvoslef-Eide M et al (2013) The touchscreen operant platform for testing learning and memory in rats and mice. Nat Protoc 8:1961-1984. doi:10.1038/nprot.2013.122

Hoyle E, Genn RF, Fernandes C, Stolerman IP (2006) Impaired performance of alpha7 nicotinic receptor knockout mice in the five-choice 
serial reaction time task. Psychopharmacology 189:211-223. doi: 10.1007/s00213-006-0549-2

International Schizophrenia Consortium (2008) Rare chromosomal deletions and duplications increase risk of schizophrenia. Nature 455: 237-241. doi:10.1038/nature07239

Javitt DC, Spencer KM, Thaker GK et al (2008) Neurophysiological biomarkers for drug development in schizophrenia. Nat Rev Drug Discov 7:68-83. doi:10.1038/nrd2463

Kahn PV, Walker TM, Williams TS et al (2012) Standardizing the use of the continuous performance test in schizophrenia research: a validation study. Schizophrn Res 142:153-158. doi:10.1016/j.schres. 2012.09.009

Kim CH, Romberg C, Hvoslef-Eide M et al (2015) Trial-unique, delayed nonmatching-to-location (TUNL) touchscreen testing for mice: sensitivity to dorsal hippocampal dysfunction. Psychopharmacology 232:3935-3945. doi:10.1007/s00213-015-4017-8

Kjaerby C, Broberg BV, Kristiansen U, Dalby NO (2014) Impaired GABAergic inhibition in the prefrontal cortex of early postnatal phencyclidine (PCP)-treated rats. Cereb Cortex 24:2522-2532. doi:10.1093/cercor/bht109

Kogan J, Gross A, Shin R (2015) Mouse model of chromosome 15q13. 3 microdeletion syndrome demonstrates features of autism spectrum disorder. J Neurosci 35:16282-16294. doi:10.1523/JNEUROSCI. 3967-14.2015

LePichon J-B, Bittel DC, Graf WD, Yu S (2010) A 15q13.3 homozygous microdeletion associated with a severe neurodevelopmental disorder suggests putative functions of the TRPM1, CHRNA7, and other homozygously deleted genes. Am J Med Genet 152A:1300-1304. doi:10.1002/ajmg.a.33374

Lewis DA, Hashimoto T, Volk DW (2005) Cortical inhibitory neurons and schizophrenia. Nat Rev Neurosci 6:312-324. doi:10.1038/ nrn1648

Lieberman JA, Dunbar G, Segreti AC et al (2013) A randomized exploratory trial of an $\alpha-7$ nicotinic receptor agonist (TC-5619) for cognitive enhancement in schizophrenia. Neuropsychopharm 38:968975. doi:10.1038/npp.2012.259

Lin H, Hsu F-C, Baumann BH et al (2014) Cortical parvalbumin GABAergic deficits with $\alpha 7$ nicotinic acetylcholine receptor deletion: implications for schizophrenia. Mol Cell Neurosci 61:163175. doi:10.1016/j.men.2014.06.007

Liu S-K, Fitzgerald PB, Daigle M et al (2009) The relationship between cortical inhibition, antipsychotic treatment, and the symptoms of schizophrenia. Biol Psychiat 65:503-509. doi:10.1016/j.biopsych. 2008.09.012

Lladó-Pelfort L, Santana N, Ghisi V et al (2012) 5-HT1A receptor agonists enhance pyramidal cell firing in prefrontal cortex through a preferential action on GABA interneurons. Cereb Cortex 22:14871497. doi:10.1093/cercor/bhr220

Lodge DJ, Behrens MM, Grace AA (2009) A loss of parvalbumincontaining interneurons is associated with diminished oscillatory activity in an animal model of schizophrenia. J Neurosci 29:23442354. doi:10.1523/JNEUROSCI.5419-08.2009

Lowther C, Costain G, Stavropoulos DJ et al (2014) Delineating the $15 q 13.3$ microdeletion phenotype: a case series and comprehensive review of the literature. Genet Med 17:149-157. doi:10.1038/gim. 2014.83

Mar AC, Horner AE, Nilsson S et al (2013) The touchscreen operant platform for assessing executive function in rats and mice. Nat Protoc 8:1985-2005. doi:10.1038/nprot.2013.123

Marder SR, Fenton W (2004) Measurement and treatment research to improve cognition in schizophrenia: NIMH MATRICS initiative to support the development of agents for improving cognition in schizophrenia. Schizophrn Res 72:5-9. doi:10.1016/j.schres.2004. 09.010

Melchior L, Bertelsen B, Debes NM et al (2013) Microduplication of $15 \mathrm{q} 13.3$ and $\mathrm{Xq} 21.31$ in a family with Tourette syndrome and comorbidities. Am J Med Genet 162:825-831. doi:10.1002/ajmg. b.32186

Michie PT, Fox AM, Ward PB et al (1990) Event-related potential indices of selective attention and cortical lateralization in schizophrenia. Psychophysiology 27:209-227. doi:10.1111/j.1469-8986.1990. tb00372.x

Miller DT, Shen Y, Weiss LA et al (2009) Microdeletion/duplication at $15 q 13.2 q 13.3$ among individuals with features of autism and other neuropsychiatric disorders. J Med Genet 46:242-248. doi:10.1136/ jmg.2008.059907

Morrow BA, Elsworth JD, Roth RH (2007) Repeated phencyclidine in monkeys results in loss of parvalbumin-containing axo-axonic projections in the prefrontal cortex. Psychopharmacology 192:283290. doi:10.1007/s00213-007-0708-0

Muir JL, Everitt BJ, Robbins TW (1996) The cerebral cortex of the rat and visual attentional function: dissociable effects of mediofrontal, cingulate, anterior dorsolateral, and parietal cortex lesions on a fivechoice serial reaction time task. Cereb Cortex 6:470-481. doi:10. 1093/cercor/6.3.470

Murakami K, Ishikawa Y, Sato F (2013) Localization of $\alpha 7$ nicotinic acetylcholine receptor immunoreactivity on GABAergic interneurons in layers I-III of the rat retrosplenial granular cortex. Neuroscience 252:443-459. doi:10.1016/j.neuroscience.2013.08. 024

Nakazawa K, Zsiros V, Jiang Z et al (2012) GABAergic interneuron origin of schizophrenia pathophysiology. Neuropharmacology 62 : 1574-1583. doi:10.1016/j.neuropharm.2011.01.022

Nieman DH, Koelman JHTM, Linszen DH et al (2002) Clinical and neuropsychological correlates of the P300 in schizophrenia. Schizophrn Res 55:105-113. doi:10.1016/S0920-9964(01)00184-0

Olincy A, Harris JG, Johnson LL et al (2006) Proof-of-concept trial of an alpha7 nicotinic agonist in schizophrenia. Arch Gen Psychiatry 63: 630-638. doi:10.1001/archpsyc.63.6.630

Oomen CA, Hvoslef-Eide M, Heath CJ et al (2013) The touchscreen operant platform for testing working memory and pattern separation in rats and mice. Nat Protoc 8:2006-2021. doi:10.1038/nprot.2013. 124

Pagnamenta AT, Wing K, Sadighi Akha E et al (2009) A 15q13.3 microdeletion segregating with autism. Eur J Hum Genet 17:687692. doi:10.1038/ejhg.2008.228

Paine TA, Slipp LE, Carlezon WA (2011) Schizophrenia-like attentional deficits following blockade of prefrontal cortex GABAA receptors. Neuropsychopharm 36:1703-1713. doi:10.1038/npp.2011.51

Passetti F, Chudasama Y, Robbins TW (2002) The frontal cortex of the rat and visual attentional performance: dissociable functions of distinct medial prefrontal subregions. Cereb Cortex 12:1254-1268. doi:10. 1093/cercor/12.12.1254

Paxinos G, Franklin KBJ (2008) The mouse brain in stereotaxic coordinates. Elsevier Academic Press, London

Pehrson AL, Bondi CO, Totah NKB, Moghaddam B (2013) The influence of NMDA and GABA(A) receptors and glutamic acid decarboxylase (GAD) activity on attention. Psychopharmacology 225: 31-39. doi:10.1007/s00213-012-2792-z

Pezze M, McGarrity S, Mason R et al (2014) Too little and too much: hypoactivation and disinhibition of medial prefrontal cortex cause attentional deficits. J Neurosci 34:7931-7946. doi:10.1523/ JNEUROSCI.3450-13.2014

Preskorn SH, Gawryl M, Dgetluck N et al (2014) Normalizing effects of EVP-6124, an alpha-7 nicotinic partial agonist, on event-related potentials and cognition. J Psychiatr Pract 20:12-24. doi:10.1097/ 01.pra.0000442935.15833.c5

Quian Quiroga R (2009) What is the real shape of extracellular spikes? J Neurosci Meth 177:194-198. doi:10.1016/j.jneumeth.2008.09.033

Robbins TW (1990) The case of frontostriatal dysfunction in schizophrenia. Schizophr Bull 16:391-402 
Robbins TW (2002) The 5-choice serial reaction time task: behavioural pharmacology and functional neurochemistry. Psychopharmacology 163:362-380. doi:10.1007/s00213-002-1154-7

Romberg C, Mattson MP, Mughal MR et al (2011) Impaired attention in the $3 \times$ TgAD mouse model of Alzheimer's disease: rescue by donepezil (aricept). J Neurosci 31:3500-3507. doi:10.1523/ JNEUROSCI.5242-10.2011

Roxborough H, Muir WJ, Blackwood DH et al (1993) Neuropsychological and P300 abnormalities in schizophrenics and their relatives. Psychol Med 23:305-314. doi:10.1017/ S0033291700028385

Snitz BE, Macdonald AW, Carter CS (2006) Cognitive deficits in unaffected first-degree relatives of schizophrenia patients: a metaanalytic review of putative endophenotypes. Schizophr Bull 32: 179-194. doi:10.1093/schbul/sbi048

Stefansson H, Meyer-Lindenberg A, Steinberg S et al (2014) CNVs conferring risk of autism or schizophrenia affect cognition in controls. Nature 505:361-366. doi:10.1038/nature12818

Steward O, Tomasulo R, Levy WB (1990) Blockade of inhibition in a pathway with dual excitatory and inhibitory action unmasks a capability for LTP that is otherwise not expressed. Brain Res 516:292300. doi:10.1016/0006-8993(90)90930-A

Stocker M, Krause M, Pedarzani P (1999) An apamin-sensitive Ca2+activated $\mathrm{K}+$ current in hippocampal pyramidal neurons. Proc Natl Acad Sci U S A 96:4662-4667

Tepper JM, Martin LP, Anderson DR (1995) GABAA receptor-mediated inhibition of rat substantia nigra dopaminergic neurons by pars reticulata projection neurons. J Neurosci 15:3092-3103

Totah NKB, Kim YB, Homayoun H, Moghaddam B (2009) Anterior cingulate neurons represent errors and preparatory attention within the same behavioral sequence. J Neurosci 29:6418-6426. doi:10. 1523/JNEUROSCI.1142-09.2009

Tse MT, Piantadosi PT, Floresco SB (2015) Prefrontal cortical gamma-aminobutyric acid transmission and cognitive function: drawing links to schizophrenia from preclinical research. Biol Psychiat 77:929-939. doi:10.1016/j.biopsych. 2014.09.007

Tseng KY, Lewis BL, Hashimoto T et al (2008) A neonatal ventral hippocampal lesion causes functional deficits in adult prefrontal cortical interneurons. J Neurosci 28:12691-12699. doi:10.1523/ JNEUROSCI.4166-08.2008

Umbricht D, Keefe RSE, Murray S et al (2014) A randomized, placebocontrolled study investigating the nicotinic $\alpha 7$ agonist, RG3487, for cognitive deficits in schizophrenia. Neuropsychopharmacol 39: 1568-1577. doi:10.1038/npp.2014.17

Volk D, Austin MC, Pierri J et al (2001) GABA transporter-1 mRNA in the prefrontal cortex in schizophrenia: decreased expression in a subset of neurons. Am J Psychiat 158:256-265. doi:10.1176/appi. ajp.158.2.256

Weisbrod M, Hill H, Niethammer R, Sauer H (1999) Genetic influence on auditory information processing in schizophrenia: P300 in monozygotic twins. Biol Psychiat 46:721-725. doi:10.1016/S00063223(99)00022-0

Winters BD, Saksida LM, Bussey TJ (2008) Object recognition memory: neurobiological mechanisms of encoding, consolidation and retrieval. Neurosci Biobehav Rev 32:1055-1070. doi:10.1016/j.neubiorev. 2008.04.004

Wobrock T, Schneider M, Kadovic D et al (2008) Reduced cortical inhibition in first-episode schizophrenia. Schizophrn Res 105:252-261. doi:10.1016/j.schres.2008.06.001

Young JW, Finlayson K, Spratt C et al (2004) Nicotine improves sustained attention in mice: evidence for involvement of the $\alpha 7$ nicotinic acetylcholine receptor. Neuropsychopharmacol 29:891900. doi:10.1038/sj.npp.1300393

Young JW, Crawford N, Kelly JS et al (2007) Impaired attention is central to the cognitive deficits observed in alpha 7 deficient mice. Eur Neuropsychopharm 17:145-155. doi:10.1016/j.euroneuro.2006.03.008 